The Application of Some Linear Feedback Control Strategies on 3D Chaotic System

\author{
Mahasin Thabit Younis \\ mahasinthabit@uomosul.edu.iq \\ College of Computer Sciences and Mathematics \\ University of Mosul, Mosul, Iraq
}

Received on: 25/07/2018

\title{
ABSTRACT
}

Accepted on: 27/08/2018

This paper tackles to some linear feedback control strategies, where we take a 3D chaotic system with a five critical point of unstability, which is discovered by scientist [Zhu Congxu, 2010]. So we applied some linear feedback strategies: first strategy Ordinary Feedback Control and the second strategy Dislocate Feedback Control on this system at origin point and we noticed that a necessary condition for suppression is getting positive feedback coefficient; but this condition fails at some strategies. For this reason, we focused on these cases in our search, and design more than a strategy for studying these different situations. Theoretical analysis and numerical simulation check the validity of the results obtained.

Keywords : Chaos Theory, Dynamical Systems, Control Systems, Ordinary Feedback Control.

$$
\begin{aligned}
& \text { تطبيق بعض استراتيجيات سيطرة التفذية الخطية الاسترجاعية على نظام ثلاثي } \\
& \text { محاسن ثابت يونس } \\
& \text { كلية علوم الحاسوب والرياضيات } \\
& \text { جامعة الدوصل، الموصل، العراق }
\end{aligned}
$$

\section{تاريخ قبول البحث: 2018/08/27}

تاريخ استلام البحث: 2018/07/25

\section{الملخص}

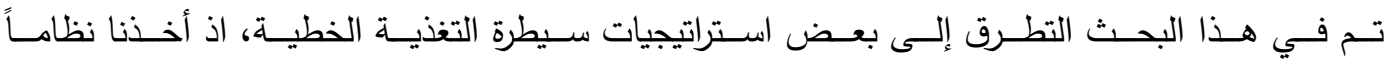

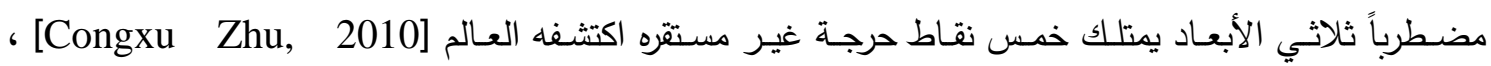

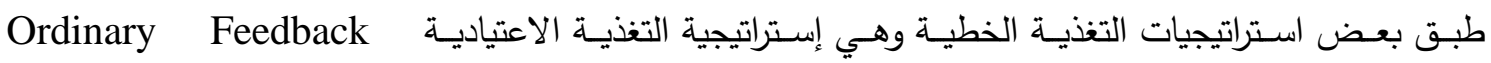
Control

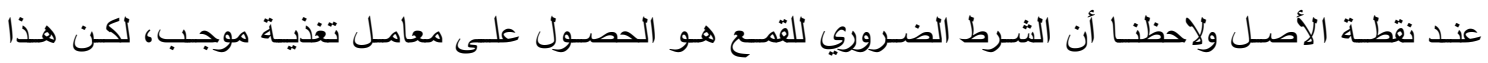

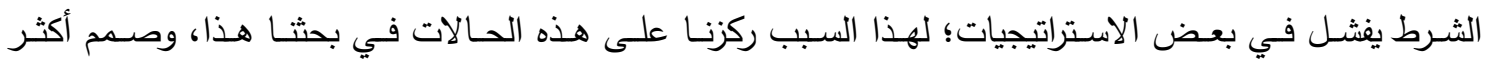

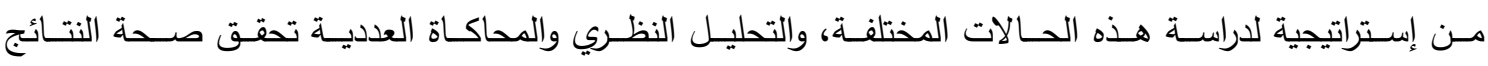
التي حصلنا عليها. الكلمات المفتاحية: نظرية الفوضى، الانظمة الديناميكية، انظمة السيطرة، التغذية الخطية الاسترجاعية.

\section{Introduction}

One can view the dynamical systems as the result of some physical systems that have evolved over time, such as planetary motion under the influence of gravity. If we wanted to know the fate of this system for a long period of time, for example, is that the planets in this system and in an infinite period of time will collide and that this system will remain the same in all cases. For some systems (such as two planet) ones these simple questions are evident to answer in the delightful system (planetary motion) is stable and balanced. But in some interesting and complex systems malfunction might 
occur and sometimes even spacing initial conditions and that is why we study some chaotic dynamic systems [8].

In 1963 American scientist Edward Lorenz discovered the first chaotic system by accident through his work in meteorology and the first contributors to the chaos, which coined the term butterfly effect. Chaotic systems have been studied for over 45 years. And since then many theories developed to analyze and synthesis chaotic systems and made many studies in this field [5].

Chaos has been well-known within the scientific, engineering and mathematical communities as an interesting, complex, dynamical phenomenon. In days, the traditional trend to understand and analyze the situation of chaos to a new phase of the investigation: control and create chaos. More specifically, if the system is stable, be useful in this case, then chaos is useful. As mentioned earlier in the system of planetary motion. However, if the system is chaotic, chaos in this case is harmful and cause many problems, so we must control the chaotic system. In fact, many studies have shown that chaos can be useful or has great potential in many disciplines, and most importantly concern advanced techniques with synchronized chaos. In recent years, controlling and synchronization has become of interesting topics more and more to engineering. Therefore, I suggest different controllers to stabilize the chaotic systems [1] and [2] and [6]. The term feedback refers to having two or more dynamical systems strongly coupled with each other so that if one was affected by these systems in response to external stimulation, either over time or forcing effect sometimes, simply we can say that in this situation it's difficult to control one of these; The first system affected by the second system also second system is influenced by the first system, so we must be use feedback system. In this case we must treat the system as a whole to understand the behavior of a chaotic system [3]. To use the feedback system, chaotic systems feedback algorithms depends mainly on Lyapunov exponent especially if you find positive value one or more of Lyapunov exponent and this is the primary reason for the existence of controller [7].

In 2010 the scientists Zhu, C and Liu, Y. introduced new 3D continuous quadratic autonomous chaotic system, modified from the Lorenz system, and analyzed by means of Lyapunove exponent spectrum, Poincaré mapping, fractal dimension, power spectrum and chaotic behaviors. This new attractors proposed can be also realized with an electronic circuit and have great potential for communication and electronics [9]. Also In 2014 Ali R. and Ziabari, M. T. introduced same as chaotic system and controlled by generalized backstepping method [2].

\section{Definitions}

\section{Definition (1): Ordinary Feedback Control}

In this method we multiple system's variables by unit control and added to unstable a chaotic system provided equivalents to be corresponding to the added variable [4].

\section{Definition (2): Dislocate Feedback Control}

In this method we multiple system's variables by unit control and added to unstable a chaotic system provided equivalents to be contrary to the added variable [4]. 


\section{Properties of Chaotic System}

The three-dimensional autonomous chaotic system with seven terms and three nonlinear described by the following differential equations [2] and [9]:

$\dot{x}=-x-u y+y z$
$\dot{y}=v y-x z$
$\dot{z}=-w z+x y$

Where $\mathrm{u}, \mathrm{v}$, and $\mathrm{w}$ are real constant parameters and of system (1) if $\mathrm{u}=\frac{3}{2}, \mathrm{v}=\frac{5}{2}$, $\mathrm{w}=\frac{49}{10}$ and the following figure described the attractors for this system.

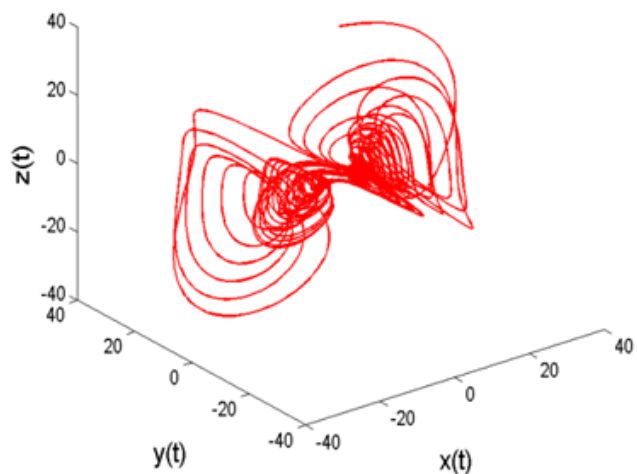

(1) $x-y-Z$ space

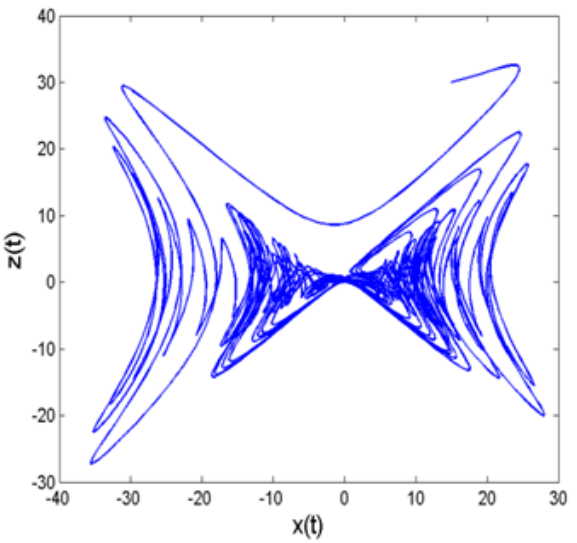

(3) $x$-z plane

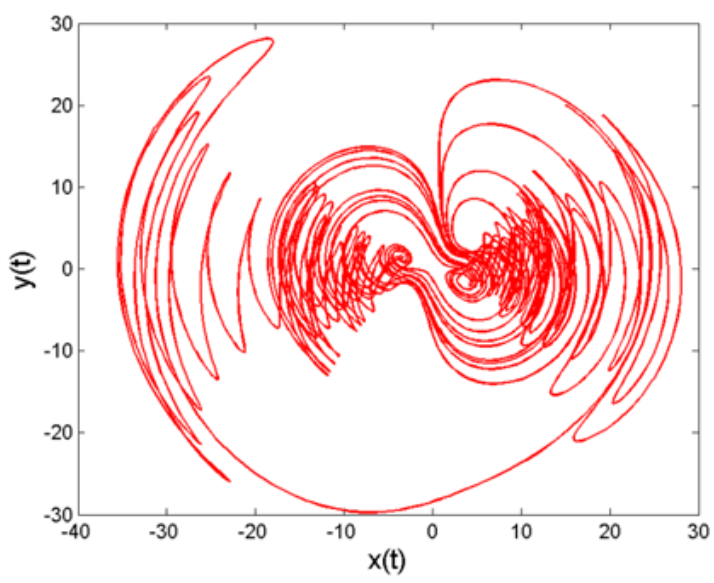

(2) $x-y$ plane

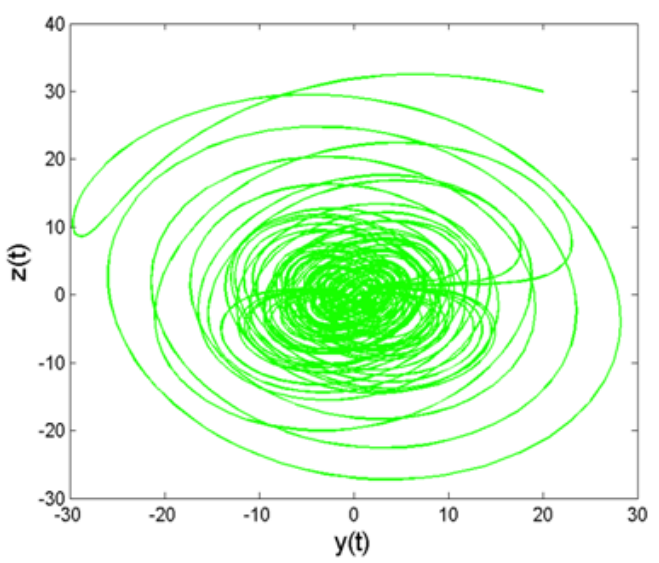

(4) $y$-z plane

Figure (1):Attractor of the chaotic system

\section{System Equilibrium}

Assume that $\mathrm{v} \neq 0, \mathrm{v}, \mathrm{w}>0$, and $\mathrm{u}^{2}+4 \mathrm{v}>0$. The equilibrium of Eq.(1) have been found by solving three equations $\dot{x}=\dot{y}=\dot{z}=0$. It is found that system (1) has five equilibrium, which are: $\mathrm{P}_{1}(0,0,0) ; \mathrm{P}_{2}\left(\mathrm{x}_{0}, \mathrm{y}_{+}, \mathrm{z}_{+}\right) ; \mathrm{P}_{3}\left(\mathrm{x}_{0}, \mathrm{y}_{-}, \mathrm{z}_{-}\right) ; \mathrm{P}_{4}\left(-\mathrm{x}_{0},-\mathrm{y}_{-}, \mathrm{z}_{-}\right) ; \mathrm{P}_{5}\left(-\mathrm{x}_{0}\right.$, $\left.-\mathrm{y}_{+}, \mathrm{z}_{+}\right)$[9].

where $\quad x_{0}=(v w)^{0.5}$. 


$$
\begin{array}{cc}
y_{+}= & \frac{1}{2 v}\left((v w)^{0.5}\left(u+\left(u^{2}+4 v\right)^{0.5}\right)\right) . \\
z_{+}=0.5\left(\left(u+\left(u^{2}+4 v\right)^{0.5}\right)\right) . & y_{-}=\frac{1}{2 v}\left((v w)^{0.5}\left(u-\left(u^{2}+4 v\right)^{0.5}\right)\right) .
\end{array}
$$

when $\mathrm{u}=\frac{3}{2}, \mathrm{v}=\frac{5}{2}, \mathrm{w}=\frac{49}{10}$, the five equilibriums are;

$$
\mathrm{P}_{1}=\left[\begin{array}{l}
0 \\
0 \\
0
\end{array}\right], \quad \mathrm{P}_{2}=\left[\begin{array}{l}
\frac{7}{2} \\
\frac{7}{2} \\
\frac{5}{2}
\end{array}\right], \quad \mathrm{P}_{3}=\left[\begin{array}{c}
\frac{7}{2} \\
7 \\
-\frac{7}{5} \\
-1
\end{array}\right], \quad \mathrm{P}_{4}=\left[\begin{array}{c}
-\frac{7}{2} \\
7 \\
\frac{7}{5} \\
-1
\end{array}\right], \quad \mathrm{P}_{5}=\left[\begin{array}{c}
-\frac{7}{2} \\
-\frac{7}{2} \\
\frac{5}{2}
\end{array}\right]
$$

for system (1) the Jacobian matrix [9] :

$$
J=\left[\begin{array}{lll}
\frac{\partial \mathrm{h}_{1}(\mathrm{X})}{\partial \mathrm{x}} & \frac{\partial \mathrm{h}_{1}(\mathrm{X})}{\partial \mathrm{y}} & \frac{\partial \mathrm{h}_{1}(\mathrm{X})}{\partial \mathrm{z}} \\
\frac{\partial \mathrm{h}_{2}(\mathrm{X})}{\partial \mathrm{x}} & \frac{\partial \mathrm{h}_{2}(\mathrm{X})}{\partial \mathrm{y}} & \frac{\partial \mathrm{h}_{2}(\mathrm{X})}{\partial \mathrm{z}} \\
\frac{\partial \mathrm{h}_{3}(\mathrm{X})}{\partial \mathrm{x}} & \frac{\partial \mathrm{h}_{3}(\mathrm{X})}{\partial \mathrm{y}} & \frac{\partial \mathrm{h}_{3}(\mathrm{X})}{\partial \mathrm{z}}
\end{array}\right]=\left[\begin{array}{ccc}
-1 & \mathrm{z}-\mathrm{u} & \mathrm{y} \\
-\mathrm{z} & \mathrm{v} & -\mathrm{x} \\
\mathrm{y} & \mathrm{x} & -\mathrm{w}
\end{array}\right]
$$

when we apply this method to control the chaotic of the system (1). Assume that we have chaotic system has the form [4]:

$\dot{\mathrm{X}}=\mathrm{AX}+\mathrm{h}(\mathrm{X})$

Where

$X(t)=\left[x_{i}\right]^{T}=\left[x_{1}, x_{2}, \ldots, x_{n}\right]^{T} \in R^{n+1}, i=1,2, \ldots, n$.

$\mathrm{A}=\left(\mathrm{a}_{\mathrm{ij}}\right)_{\mathrm{n} \times \mathrm{n}}$ is matrix parameters, $\mathrm{h}: \mathrm{R}^{\mathrm{n}} \rightarrow \mathrm{R}^{\mathrm{n}}$ is the nonlinear part of the system . If we add the unit control to the Eq.(3), then the system controlled has the form:

$\dot{\mathrm{X}}=\mathrm{AX}+\mathrm{h}(\mathrm{X})+\mathrm{N}$

The purpose unit control to make $\lim _{t \rightarrow \infty}\|X(t)\|=0$. We can present unit control by the form:

$$
\mathrm{N}=\mathrm{n}_{\mathrm{i}}=\left\{\begin{array}{cc}
-\mathrm{kx}_{\mathrm{i}} & ; \text { ifi }=\mathrm{j} \text { (ordinary) } \\
-\mathrm{kx}_{\mathrm{j}} & ; \text { ifi } \neq \mathrm{j} \text { (dislocate) }
\end{array}\right\}
$$

Such that $\mathrm{k}$ is feedback parameters and $\mathrm{k}>0$. This method depends on Routh Hurwitz Theorem, to find exact value of feedback parameter the necessary and sufficient condition to satisfy chaotic control and the feedback parameter must be positive, some time we get more than positive feedback parameter, to select good feedback parameter we use the equation [4]:

$\mathrm{k}=\bigcap_{\mathrm{i}=1}^{\mathrm{n}} \mathrm{k}_{\mathrm{i}}=\mathrm{k}_{1} \cap \mathrm{k}_{2} \cap \ldots \cap \mathrm{k}_{\mathrm{n}}$

the system (1) has been written by the formula [2] and [9]:

$$
\left[\begin{array}{c}
\dot{x} \\
\dot{y} \\
\dot{z}
\end{array}\right]=\left[\begin{array}{rcr}
-1 & -u & 0 \\
0 & v & 0 \\
0 & 0 & -w
\end{array}\right]\left[\begin{array}{l}
\mathrm{x} \\
\mathrm{y} \\
\mathrm{z}
\end{array}\right]+\left[\begin{array}{c}
\mathrm{yz} \\
-\mathrm{xz} \\
\mathrm{xy}
\end{array}\right]
$$


Characteristic Equation founded by using $\operatorname{det}\left(\mathrm{J}_{\mathrm{P}_{1}}-\lambda \mathrm{I}\right)=0$, and we get

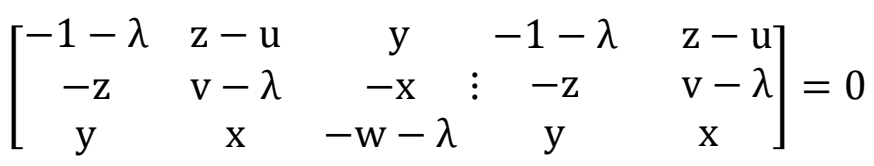

$(-1-\lambda)(\mathrm{v}-\lambda)(-\mathrm{w}-\lambda)-(\mathrm{z}-\mathrm{u})(\mathrm{xy})-(\mathrm{xyz})-$

$(\mathrm{v}-\lambda) \mathrm{y}^{2}+(-1-\lambda) \mathrm{x}^{2}+(-\mathrm{w}-\lambda)(\mathrm{z}-\mathrm{u}) \mathrm{z}=0$

The characteristic equation of the point $\mathrm{P}_{1}(0,0,0)$ has the form

$\lambda^{3}+(w+1-v) \lambda^{2}+(w-v-w v) \lambda-w v=0$

$\lambda^{3}+(\mathrm{w}+1-\mathrm{v}) \lambda^{2}+(\mathrm{w}-\mathrm{v}-\mathrm{wv}) \lambda-\mathrm{wv}=0$

when $\mathrm{u}=\frac{3}{2}, \mathrm{v}=\frac{5}{2}, \mathrm{w}=\frac{49}{10} \mathrm{We}$ get:

$\lambda^{3}+3.4 \lambda^{2}-9.85 \lambda-12.25=0$

The eigenvalues of characteristic the Eq. (7) are $\lambda_{1}=-1, \lambda_{2}=\frac{5}{2}$ and

$\lambda_{3}=-\frac{49}{10}$. Here $\lambda_{2}$ is a not negative real number, $\lambda_{1}$ and $\lambda_{3}$ real numbers are two negative. So that, the point $\mathrm{P}_{1}(0,0,0)$ is a saddle point. Also this point $\mathrm{P}_{1}(0,0,0)$ is unstable. For each of the four equilibrium points $\mathrm{P}_{2}, \mathrm{P}_{3}, \mathrm{P}_{4}$ and $\mathrm{P}_{5}$, the results show that $\lambda_{1}$ is a negative, $\lambda_{2}$ and $\lambda_{3}$ become a pair of complex conjugate eigenvalues with not negative real parts. all, equilibrium points $\mathrm{P}_{2}, \mathrm{P}_{3}, \mathrm{P}_{4}$ and $\mathrm{P}_{5}$ are all saddle-focus points; so, these equilibrium points are all unstable [2] and [9].

\section{Theorems}

Theorem (1): The system (1) with control $\mathrm{N}=\left[\begin{array}{c}0 \\ \mathrm{n}_{2} \\ 0\end{array}\right]$ and $\mathrm{n}_{2}=-\mathrm{ky}$, based on ordinary feedback control, then the system (1) converge to the unstable equilibrium $\mathrm{P}_{1}$ when $\mathrm{k} \in(2.5, \infty)$.

Proof : The system(1) and new control can be written in the form :

$\left[\begin{array}{l}\mathrm{x} \\ \mathrm{y} \\ \mathrm{z}\end{array}\right]=\left[\begin{array}{ccc}-1 & \mathrm{z}-\mathrm{u} & 0 \\ -\mathrm{z} & \mathrm{v} & 0 \\ 0 & \mathrm{x} & -\mathrm{w}\end{array}\right]\left[\begin{array}{l}\mathrm{x} \\ \mathrm{y} \\ \mathrm{z}\end{array}\right]+\left[\begin{array}{c}0 \\ -\mathrm{ky} \\ 0\end{array}\right]$

Then the characteristic Eq. is:

$\lambda^{3}+(3.4+\mathrm{k}) \lambda^{2}+(5.9 \mathrm{k}-9.85) \lambda+(4.9 \mathrm{k}-12.25)=0$

$\mathrm{D}=(3.4+\mathrm{k}), \quad \mathrm{E}=(5.9 \mathrm{k}-9.85)$ and $\mathrm{F}=(4.9 \mathrm{k}-12.25)$

Now, according to the Routh-Hurwitz Theorem, the Eq. (9) has three eigenvalues all of them are real part and negative if the three conditions are satisfied:
1) D $>0$
2) $\mathbf{F}>0$
3) $\mathbf{D E}-\mathbf{F}>0$ 
Obviously, from $\mathrm{D}=(3.4+\mathrm{k})>0$, from $\mathrm{F}=(4.9 \mathrm{k}-12.25)>0$, we have a positive feedback coefficient such that $\mathrm{k}>2.5$. Lastly, from the third condition, we have quadratic equation whose form:

$5.9 \mathrm{k}^{2}+5.31 \mathrm{k}-21.24>0$

By solving the above the inequality of the Eq. (10) we get another positive feedback coefficient as $\mathrm{k}>1.5$, so that the active feedback control when $\mathrm{k}>2.5$. After testing if we notice that the positive feedback coefficientk $>2.5$ is effective and active on the system (1). Let us take some values of $\mathrm{k}$ and substitute this value in the Eq. (9) we have the following Table 1:

Table (1) List of eigenvalues corresponding to the characteristic Eq. (9) for different values of $\mathbf{k}$

\begin{tabular}{|c|c|c|}
\hline Value of $k$ & Characteristic Eq. & Eigenvalues \\
\hline 2 & $\lambda^{3}+5.4 \lambda^{2}+1.95 \lambda+2.45=0$ & $\begin{array}{l}\lambda_{1}=-4.9 \\
\lambda_{2}=-1 \\
\lambda_{3}=0.5\end{array}$ \\
\hline 2.5 & $\lambda^{3}+5.9 \lambda^{2}+4.9 \lambda=0$ & $\begin{array}{c}\lambda_{1}=-4.9 \\
\lambda_{2}=-1 \\
\lambda_{3}=0 \\
\end{array}$ \\
\hline 3 & $\lambda^{3}+6.4 \lambda^{2}+7.85 \lambda+2.45=0$ & $\begin{array}{c}\lambda_{1}=-4.9 \\
\lambda_{2}=-1 \\
\lambda_{3}=-0.5\end{array}$ \\
\hline
\end{tabular}
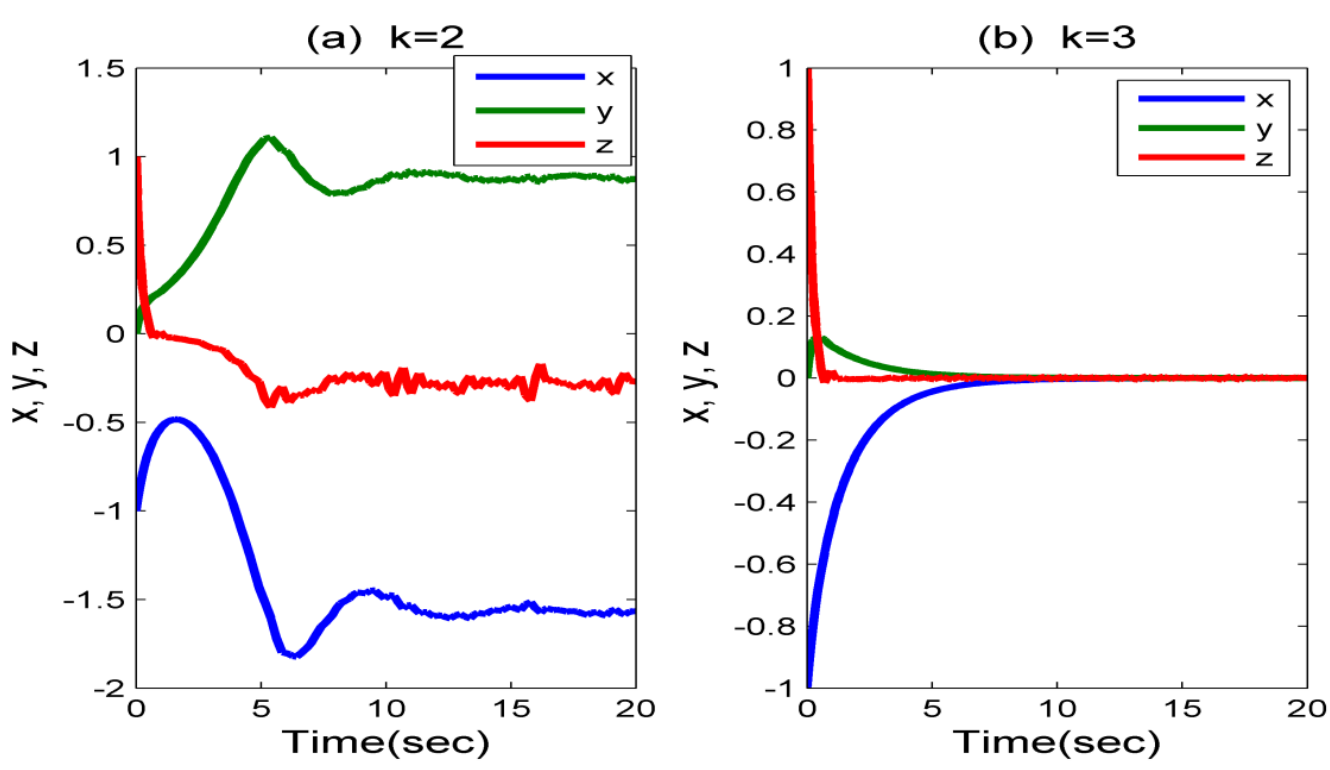

Figure(2) Stabilization of system.

This method is achieved to control system (1), because it has satisfied all three conditions of R.H. T. and all eigenvalues that have got it negative, so we can control the behavior of the system and made it stable. The proof is completed. 
Theorem (2): The system(1) with control $\mathrm{N}=\left[\begin{array}{c}\mathrm{n}_{1} \\ 0 \\ 0\end{array}\right]$ and, $\mathrm{n}_{1}=-\mathrm{kx}$, based on ordinary feedback control, can't be controlled. Although, we get one positive feedback coefficient $\mathrm{k}>1.5$

Proof : The system(1)and new control can be written as in the form:

$\left[\begin{array}{c}\dot{x} \\ \dot{y} \\ \dot{y}\end{array}\right]=\left[\begin{array}{ccc}-1 & \mathrm{z}-\mathrm{u} & 0 \\ -\mathrm{z} & \mathrm{v} & 0 \\ 0 & \mathrm{x} & -\mathrm{w}\end{array}\right]\left[\begin{array}{l}\mathrm{x} \\ \mathrm{y} \\ \mathrm{z}\end{array}\right]+\left[\begin{array}{c}-\mathrm{kx} \\ 0 \\ 0\end{array}\right]$

Then the characteristic Eq. is:

$\lambda^{3}+(3.4+\mathrm{k}) \lambda^{2}+(2.4 \mathrm{k}-9.85) \lambda-12.25(\mathrm{k}+1)=0$

Obviously $\mathrm{D}=(3.4+\mathrm{k}), \mathrm{E}=(2.4 \mathrm{k}-9.85)$ and $\mathrm{F}=-12.25 \mathrm{k}-12.25$, if we solve this $\mathrm{k}<-3.4$ which implies that the first condition of R. H. T. isn't satisfying (also second condition ). Although,we have one positive feedback coefficient it's $\mathrm{k}>1.5$.

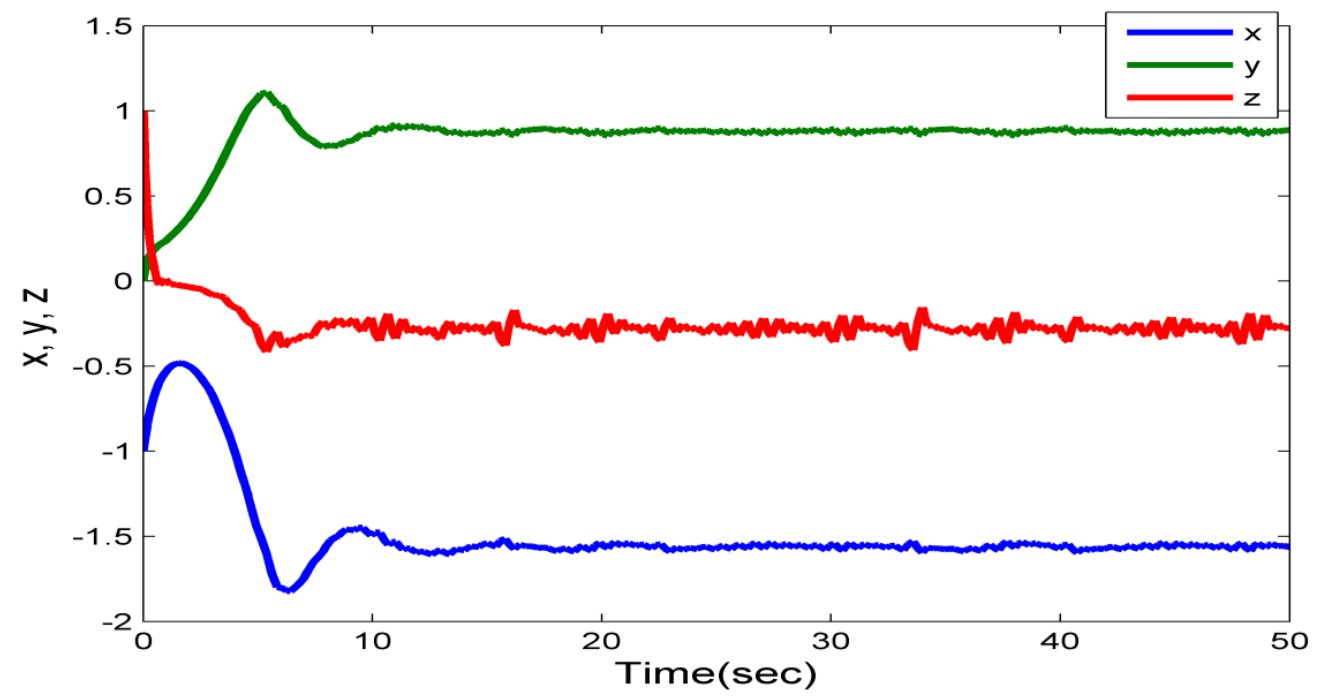

Figure(3) Numerical simulation of control

Therefore, the method is failing to control this system. Also system(1) with control $\mathrm{N}=\left[\begin{array}{c}0 \\ 0 \\ \mathrm{n}_{3}\end{array}\right]$ and, $\mathrm{n}_{3}=-\mathrm{kz}$, can't be controlled. The proof is completed.

Theorem (3): System (1) with control $N=\left[\begin{array}{c}0 \\ n_{2} \\ 0\end{array}\right]$ and, $n_{2}=-k x$, based on Dislocate

feedback control, can't be control because not all parameter of characteristic equation is positive.

\section{Proof:}

System(1)and new control can be written as the form:

$\left[\begin{array}{c}\dot{\mathrm{x}} \\ \dot{\mathrm{y}} \\ \dot{\mathrm{z}}\end{array}\right]=\left[\begin{array}{ccc}-1 & \mathrm{z}-\mathrm{u} & 0 \\ -\mathrm{z} & \mathrm{v} & 0 \\ 0 & \mathrm{x} & -\mathrm{w}\end{array}\right]\left[\begin{array}{l}\mathrm{x} \\ \mathrm{y} \\ \mathrm{z}\end{array}\right]+\left[\begin{array}{c}0 \\ -\mathrm{kx} \\ 0\end{array}\right]$

Then the characteristic Eq.

$\lambda^{3}+3.4 \lambda^{2}-(1.5 \mathrm{k}+9.85) \lambda-(7.35 \mathrm{k}+12.25)=0$ 
Obviously $\mathrm{D}=3.4, \mathrm{E}=(-1.5 \mathrm{k}-9.85) \mathrm{andF}=-(7.35+12.25 \mathrm{k})$, from the first condition of R. H. T. is satisfied. But the ( second and third condition) aren't satisfying. Therefore we can't apply R. H. T. in this case. So that, the method of Dislocate Feedback Control fail to control system (1).

By solving the other cases in this method, note that the system(1) with control $N=\left[\begin{array}{l}n_{1} \\ n_{2} \\ n_{3}\end{array}\right]$ and, $n_{i}=-k x_{j}, i \neq$ jfor all variable $x, y, z$. We get the characteristic Eq.(14) hasn't controlled feedback k. Therefore the method of Dislocate Feedback Control is fail to control system (1). The proof is completed.

\section{Conclusion}

In this paper we have solved some strategies of $3 \mathrm{D}$ continuous chaotic system. Basic properties depend mainly on Lyapunove exponents to determine system is chaotic or stable. We have also transformed this chaotic system by using some strategies to stable system (Ordinary Feedback Control and Dislocate Feedback Control) and through the results obtained show that the only way to make the system stable is in Ordinary Feedback Control method. But When used Dislocate Feedback Control fail to control the chaotic system, that's explain theoretical and numerical result. 


\section{REFERENCES}

[1] Ali. R.S. \& Ziabari, M. T \& Seyed Amin S. A. (2010)"Chaos Control via Optimal Generalized Backstepping Method". International Review of Electrical Engineering Vol.5, No.5.pp.( 2129-2140)

[2] Ali. R.S.\& Ziabari, M. T. (2014) "Control of New 3D Chaotic System", International Journal of Information Technology, Modeling and Computing Vol. 2, No. 1, pp. (69-75).

[3] Aström, K. J. \&Murray, R. M.(2007). "Feedback Systems An Introduction for Scientists and Engineers".

[4] Aziz, M. M.\& AL-Azzawi, S. F. (2017) "Some Problems of Feedback Control Strategies and It's Treatment", Canadian Center of Scince and Education, Journal of Mathematics Reesearch; Vol. 9, No. 1, pp. (39-49).

[5] Emad , M. E,(2012)"Dynamics and synchronization of new hyperchaotic complex Lorenz system", Mathematical and Computer Modeling 55 , pp. (19511962).

[6] Faqiang,W. \&Chongxin, L. (2006) "A new criterion for chaos and hyperchaos synchronization using linear feedback control", Physics Letters A 360, pp. (274278).

[7] khlef , I. \& Mansouri, N. (2012), "Hyperchaotification and Synchronization of Chaotic Systems", International Journal of Control Science and Engineering 2012, 2(4):pp.( 69-74).

[8] Teschl, G. (2012) "Ordinary Differential Equations and Dynamical Systems", the American Mathematical Society.

[9] Zhu, C. \& Liu, Y. \&Guo, Y. ,(2010)"Theoretic and Numerical Study of a New Chaotic System" Intelligent Information Management, 2, pp. ( 104-109). 